\title{
Decision analysis of agroforestry options reveals adoption risks for resource-poor farmers
}

\author{
Hoa Do ${ }^{1}$ (D) $\cdot$ Eike Luedeling ${ }^{1} \cdot$ Cory Whitney ${ }^{1}$ \\ Accepted: 8 May 2020 / Published online: 9 June 2020 \\ (C) The Author(s) 2020
}

\begin{abstract}
Agroforestry interventions have the potential to benefit the livelihoods of farmers and communities worldwide. However, given the high system complexity, the long-term benefits of agroforestry are difficult to anticipate. This study aimed to integrate uncertainty into long-term performance projections for agroforestry interventions in the highlands of Northwest Vietnam. We applied decision analysis and probabilistic modeling approaches to produce economic ex-ante assessments for seven agroforestry options (intercropping of maize, forage grass, or coffee with tea, nut, fruit, and timber trees) promoted in the region. Our results indicate that farmers likely prefer annual monocultures due to the relatively early incomes and short time-lag on returns. However, the results also show that annual profits from monocrops can be expected to decrease over time, due mainly to unsustainable soil use. Agroforestry systems, on the other hand, return substantial profits in the long term, but they also incur high establishment and maintenance costs and can generate net losses in the first few years. Initial financial incentives to compensate for these losses may help in promoting agroforestry adoption in the region. Uncertainties related to farmers' time preference, crop yields, and crop prices appeared to have the greatest influence on whether monocropping or agroforestry emerged as the preferable option. Narrowing these key knowledge gaps may offer additional clarity on farmers' optimal course of action and provide guidance for agencies promoting agroforestry interventions in Vietnam and elsewhere. Our model produced a set of plausible ranges for net present values and highlighted critical variables, more clarity on which would support decision-making under uncertainty. Our innovative research approach proved effective in providing forecasts of uncertain outcomes and can be useful for informing similar development interventions in other contexts.
\end{abstract}

Keywords Decision analysis $\cdot$ Uncertainty $\cdot$ Probabilistic modeling $\cdot$ Monte Carlo simulation $\cdot$ Agroforestry

\section{Introduction}

Agroforestry has the potential to reduce poverty and improve food security while at the same time addressing land degradation and supporting the delivery of other ecosystem services (Kuyah et al. 2019). These prospects have led to the promotion of agroforestry as a sustainable land-use practice in various regions (Mbow et al. 2014; Luedeling et al. 2014; Hoang et al. 2017). However, adoption rates are still low in many regions, indicating that such systems do not always seem desirable from the farmer's perspective. Farmers often find it

Hoa Do

dohoa1190@gmail.com

1 Department of Horticultural Sciences, Institute of Crop Science and Resource Conservation, University of Bonn, Auf dem Hügel, 53121 Bonn, Germany difficult to make predictions about long-term returns on investments in agroforestry systems, due to system complexity and long planning horizons. Models to forecast agroforestry performance may be helpful when exploring optimal management practices and the best ways to raise adoption rates. Building such models requires a realistic evaluation of the performance of new practices (Luedeling and Shepherd 2016).

Cost-benefit analysis has been widely used to assess the profitability of alternative agricultural practices in developing countries (Das and Bauer 2012; Pannell et al. 2014; Sain et al. 2017). Conventional cost-benefit models, however, are often deterministic and fail to account for uncertainty or variation in model variables (Davidson et al. 2006). Actual intervention outcomes can diverge considerably from decision-makers' expectations, especially in cases where wishful thinking shapes the model assumptions and choice of input values. 
There are multiple ways to include uncertain values in calculations, including probability distributions (Rosenstock et al. 2014; Luedeling et al. 2015), conditional probability tables (Whitney et al. 2018), fuzzy numbers (Page et al. 2012), or arithmetic intervals (Davidson et al. 2006). Probability distributions are the dominant means for formally representing uncertainty, since they constitute an effective option to describe the likely values of a particular quantity (Uusitalo et al. 2015). By encoding uncertain factors as probability distributions, it is possible to derive distributions of model outputs and system performance indices. Frequently used techniques include Monte Carlo sampling (O'Hagan 2012; Luedeling et al. 2015; Sain et al. 2017) and Bayesian Networks (Whitney et al. 2018). Monte Carlo simulations have been employed to address field variability and parameter uncertainties to assess the cost-benefit profile of climate-smart agriculture options (Sain et al. 2017), to predict the range of yield benefits when adopting conservation agriculture practices (Rosenstock et al. 2014), and to project the impact of agricultural development policies on household nutrition (Whitney et al. 2017).

Decision analysis is an interdisciplinary approach that provides methods and tools to support decision-making under uncertainty (Hardaker and Lien 2010; Luedeling and Shepherd 2016). The methods offer solutions for comprehensively evaluating decision options by incorporating all the available information that is relevant to a particular decision, including scientific data and expert knowledge. Decision analysis allows explicit quantification of all relevant uncertainties. In many complex environmental systems, measured data and formal theories are limited, inconsistent, or lacking. In such cases, expert knowledge may be the best available information (Krueger et al. 2012) for supporting decision-making. Expert knowledge can come in many forms and be derived from different types of experts, including scientific specialists (Page et al. 2012), farmers, and land managers (Oliver et al. 2012). Decision analysis can harness this knowledge to obtain a qualitative understanding of a system and then translate this understanding into a set of mathematical equations (Krueger et al. 2012). The model can then be fed with data elicited from experts. Probability distributions derived from expert knowledge are widely recognized as an appropriate quantitative representation of uncertainty (Hubbard 2014). Assigning a range for a particular quantity helps to overcome the need for any assumptions of certainty, which are rarely justifiable in the analysis of real-world issues.

The complexity of development challenges calls for approaches that allow a comprehensive analysis of the expected impacts of agricultural interventions. Such approaches could support social change and help enhance the sustainability of agricultural development (Nguyen et al. 2015). Decision analysis appears highly suitable for such contexts, including agroforestry interventions in Vietnam. Decision analysis has been applied in a diversity of fields including computer science, public health, business, and natural resource management, but it is relatively new to agricultural development research (Luedeling and Shepherd 2016). Here, we demonstrate the application of decision analysis approaches for conducting a probabilistic cost-benefit analysis. We showcase the approaches by applying them to seven agroforestry options, with the aim of comparing the proposed interventions to common monoculture systems. We also use decision analysis methods to highlight important uncertainties that influence resulting recommendations.

\section{Materials and methods}

\subsection{Study objects and locations}

We applied decision analysis procedures to evaluate seven agroforestry intervention options in the Northwestern uplands of Vietnam (Fig. 2a). The region faces low crop yields and has the highest poverty rate in the country. Much of the land features steep slopes that are difficult to cultivate (87\% of the land has a slope $>25^{\circ}$; Hoang et al. 2017), with relatively infertile soils. Government reforms in the mid-1980s, aimed at de-collectivizing cultivated land and transitioning from subsistence agriculture to commodity production, dramatically changed the landscapes of the region. Growing population pressure and unclear ownership of forest land led to the expansion of cultivated land and widespread deforestation. Cash crops such as maize, cassava, paddy rice, coffee, and tea have since become the main sources of income (Hoang et al. 2017). During this transformation, agriculture intensified, leading to rising farm incomes. However, these short-term benefits have come at the expense of long-term sustainability. With the introduction of high-yielding maize varieties and the use of chemical fertilizers, fallow periods have shortened. This has led to severe soil erosion on the heavily sloping land and accelerated land degradation, leading to declines in crop yields. In order to address deforestation, eradicate hunger, and alleviate poverty, several rural development programs have been implemented in the region (Simelton et al. 2017). Among them the project "Agroforestry for livelihoods of smallholder farmers in Northwest Vietnam" (AFLi), run by the World Agroforestry (ICRAF), applies on-farm agroforestry trials to create sustainable options for upland farming systems (Fig. 1). AFLi has tested several agroforestry interventions with diverse combinations of timber trees, fruit trees, and commodity trees together with forage grass and annual crops, in order to identify the most suitable options for local conditions. Follow-up research has focused on agricultural productivity and development of tree and crop components. However, the project currently lacks any assessments of 
Fig. 1 Three agroforestry systems being promoted in Northwest Vietnam. a Coffeebased agroforestry system (Macadamia in coffee-annual crop intercrop). b Maize-based agroforestry system (Dimocarpus longan Lour. in maize system with grass strips). c Simple agroforestry system (Shan tea with forage grass)
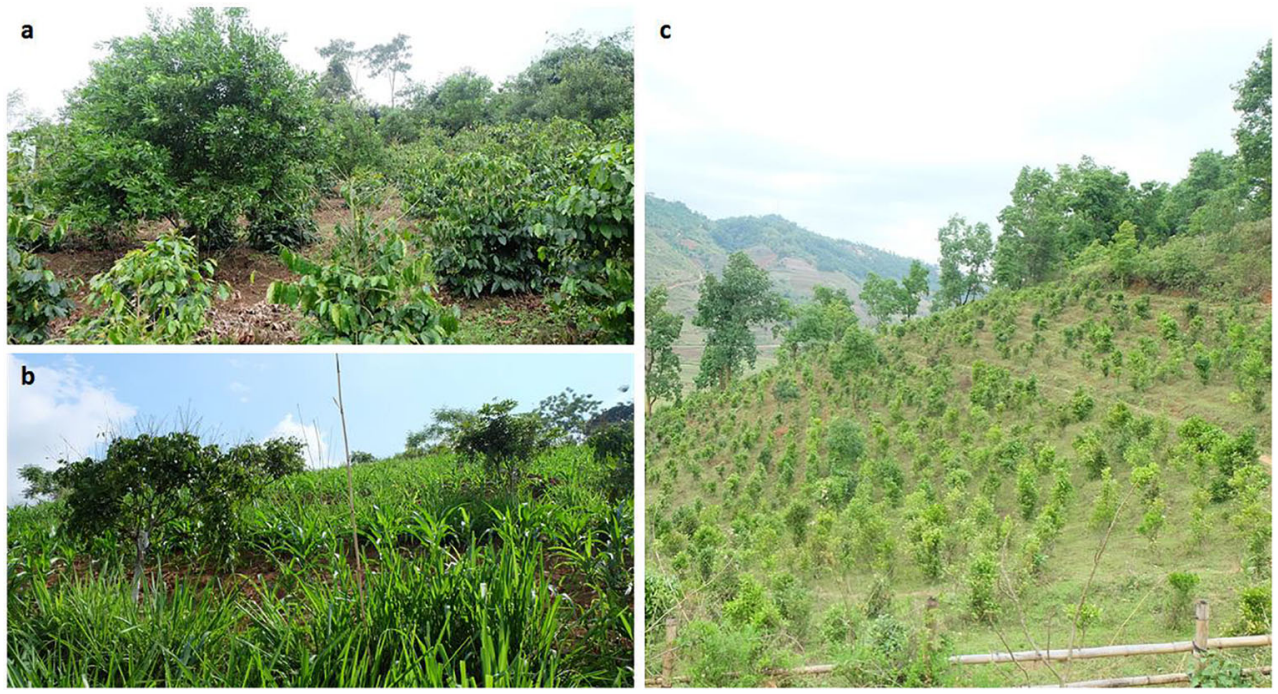

economic profitability or consideration of uncertainty. These gaps provided the motivation for the present study.

Three groups of agroforestry systems were categorized mainly based on the tree species involved. Two simple agroforestry systems (Fig. 2b) are traditional plantations of son tra
(Docynia indica (Wall.) Decne.) and Shan tea (Camellia sinensis L. Kuntze) intercropped with forage grass. In maize-based agroforestry systems (Fig. 2c), fruit trees including longan (Dimocarpus longan Lour.) and mango (Mangifera indica L.), timber Acacia (Acacia mangium

\section{a) Study regions in Northwestern Vietnam}

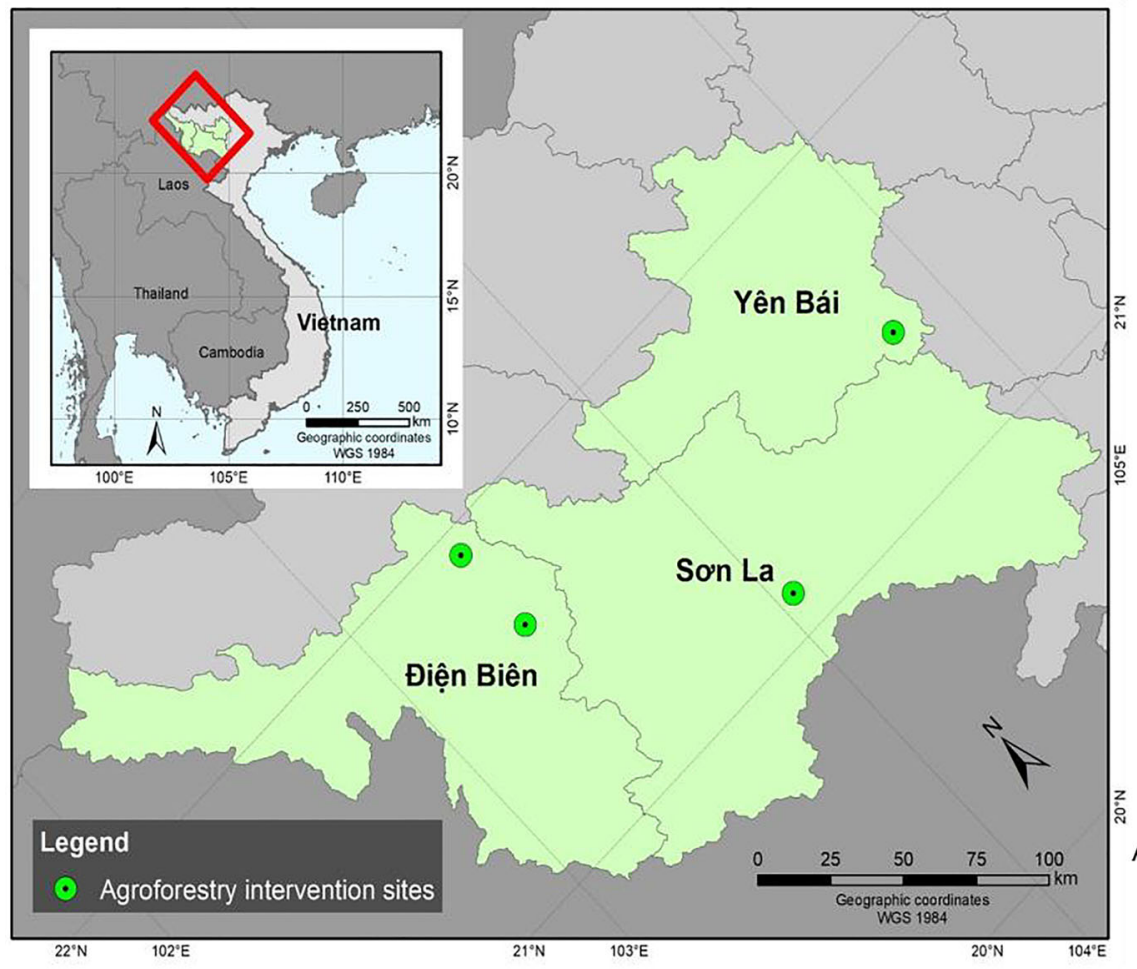

b) Simple agroforestry

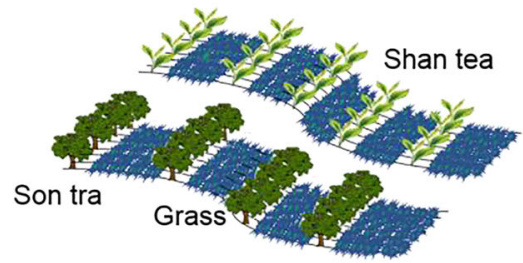

c) Maize-based agroforestry

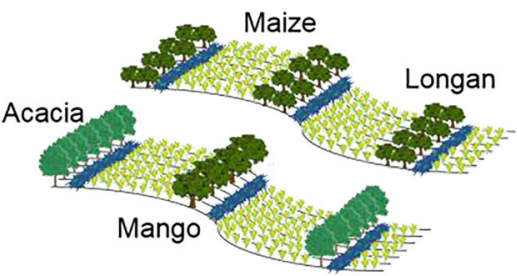

d) Coffee-based agroforestry

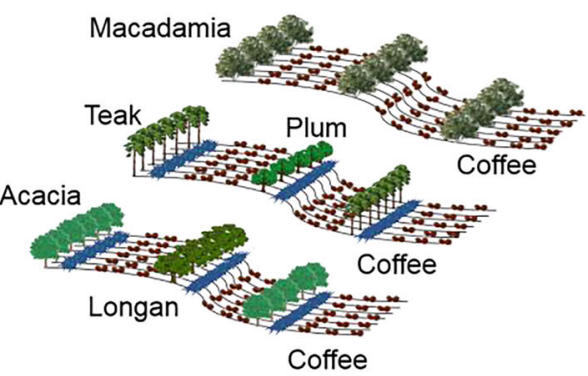

Fig. 2 Study regions (a) and agroforestry interventions in Northwest Vietnam. Maize-based agroforestry systems (b) are located at low altitudes (300-400 m above sea level) of Yen Bai province; simple agroforestry systems (c) are located at high altitudes $(>800 \mathrm{~m}$ above sea level) of Dien Bien province; coffee-based agroforestry systems (d) are located in the middle altitudes (600-800 m above sea level) of Son La and Dien Bien provinces 
Willd. and Acacia auriculiformis Benth.), and grass strips are integrated with traditional maize cultivation. Coffee-based agroforestry (Fig. 2d) consists of one intercropping system, where coffee (Coffea arabica L.) and macadamia (Macadamia integrifolia Maiden \& Betche) are cultivated together with annual crops, and two complex agroforestry systems (CAFS), where coffee is combined with timber trees including acacia and teak (Tectona grandis L.f.), fruit trees including longan and plum (Prunus salicina Lindl.), grass strips, and annual crops. Cash tree crops are grown with densities of 500 trees ha $^{-1}$ for son tra and 2240 trees ha $^{-1}$ for Shan tea in simple agroforestry systems, whereas maize-based agroforestry systems featured 240 longan trees $\mathrm{ha}^{-1}$ and 125 mango trees $\mathrm{ha}^{-1}$. The two coffee-based systems included 154 macadamia trees $\mathrm{ha}^{-1}$ intercropped with 2160 coffee trees $\mathrm{ha}^{-1}$ and 125 longan/plum trees $\mathrm{ha}^{-1}$ intercropped with 1680 coffee trees $\mathrm{ha}^{-1}$, respectively.

\subsection{Model specification}

We built a decision model following a decision analysis approach (Fig. 3) designed for research for agricultural development (Luedeling and Shepherd 2016). Twenty-one farmers who had been either engaged in agroforestry trials or had experience in the cultivation of the various tree crops were involved in the model development process as essential sources of information regarding local contexts and practices. We chose staff of the AFLi project and ICRAF's technical experts, responsible for agroforestry trials throughout the project, to be core experts for model development. We also consulted three experts from other local research institutes for their expertise and extensive research experience in related fields, e.g., fruit and coffee production.

We derived expert knowledge from one-on-one interviews with all participants, providing each of them with the opportunity to express their ideas about the structure of the decision model. We also organized discussions with groups of farmers, groups of experts, and mixed groups consisting of both farmers and experts. These discussions culminated in a consensus model structure that captured opinions and information of all stakeholders about the costs, benefits, and risks of the interventions. We also made use of our own extensive observations in the field, as well as information from relevant literature when formalizing inputs and refining the decision model.

We considered two decision alternatives, for which experts specified all costs, benefits, and risks:

Decision alternative 1: Implementation of agroforestry systems

This decision option had two main types of costs:

- Establishment costs incurred when agroforestry is adopted, including expenses for land preparation (manual or mechanical depending on local geographic and socioeconomic conditions), seedlings, and other inputs such as fertilizers, compost, herbicides, and farming equipment.
Fig. 3 Principal stages of the decision analysis approach used to study the impacts of adopting agroforestry in northwestern Vietnam

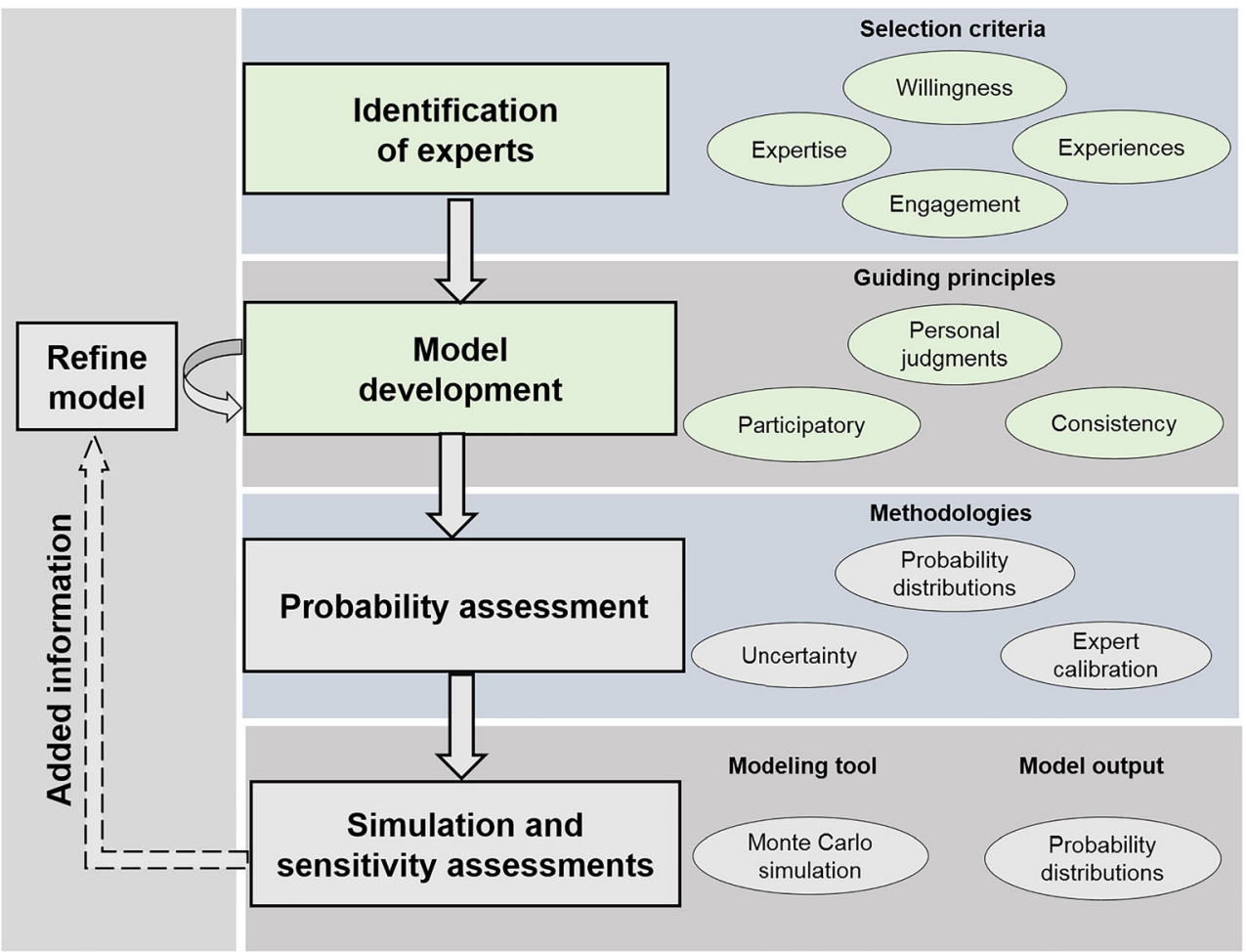


- Maintenance costs incurred annually to ensure established systems continue to operate, including costs of labor and other inputs such as fertilizer and pesticides.

The benefits of the decision options were derived mainly from revenues gained from the harvest of crop components such as fruits, nuts, coffee, timber, maize, and grass biomass.

Decision alternative 2: Maintaining conventional monocultures of maize

Under this decision option, farmers incur annual costs for fertilizer, seeds, and labor, but no installation costs are required. Benefits were calculated as the estimated income from maize production.

\subsection{Conceptualization of the decision model}

We worked together with experts to derive a conceptual model that explicitly identified all the important factors and relationships in ICRAF's agroforestry interventions (Fig. 4). Since the crop yield and input demand depend on the age of the plantation, all benefits and costs were modeled in relation to the age of the systems. The establishment cost was only incurred in the first year. Since annual input costs varied throughout the production cycle, maintenance costs were estimated corresponding to time intervals specified by experts. Risks were quantified in the model by simulating the likelihood and consequences of events perceived as consequential for farm-scale outcomes. The main consequences of these events were calculated as the decline of tree and crop yields compared to the yield in normal years (Table 1). Experts divided yield variables into component parameters, e.g., tree yields per hectare were calculated on the basis of representative individual trees multiplied by tree density in the stand. In coffee-based agroforestry systems, the revenues from annual crops were assigned for only the first 3 years, at which point annual crops would likely no longer be productive. The monetary value from soil loss prevention was estimated as the savings in fertilizer costs which would otherwise have been incurred to compensate for nutrients lost with eroded soils under monoculture maize production.

Impacts of extreme weather were considered as the most important risks and modeled explicitly. Problematic extreme weather events in the Northwest include frosts, droughts, and hot and dry winds, which negatively affect crop production. Winter frosts are the greatest threat to coffee production in the region. Hot and dry winds blowing from Laos in summer threaten fruit trees and maize production. The winds cause a quick reduction in humidity and speed up evapotranspiration. Together with frequent drought in the region, the winds can induce premature flower and fruit drop in fruit trees and cause yield loss in maize.

External factors such as crop prices and discount rates were also included in the evaluation for both decision alternatives. The causal impact model generated through these processes was then converted into a mathematical model to enable simulation of agroforestry outcomes. The resulting simulation model considered all the factors included in the conceptual
Fig. 4 Conceptual model of costbenefit analysis incorporating risk factors for agroforestry planning in Northwest Vietnam. "Tree yield" indicates Shan tea harvest, son tra fruits, longan fruits, mango fruits, plum fruits, and macadamia nuts

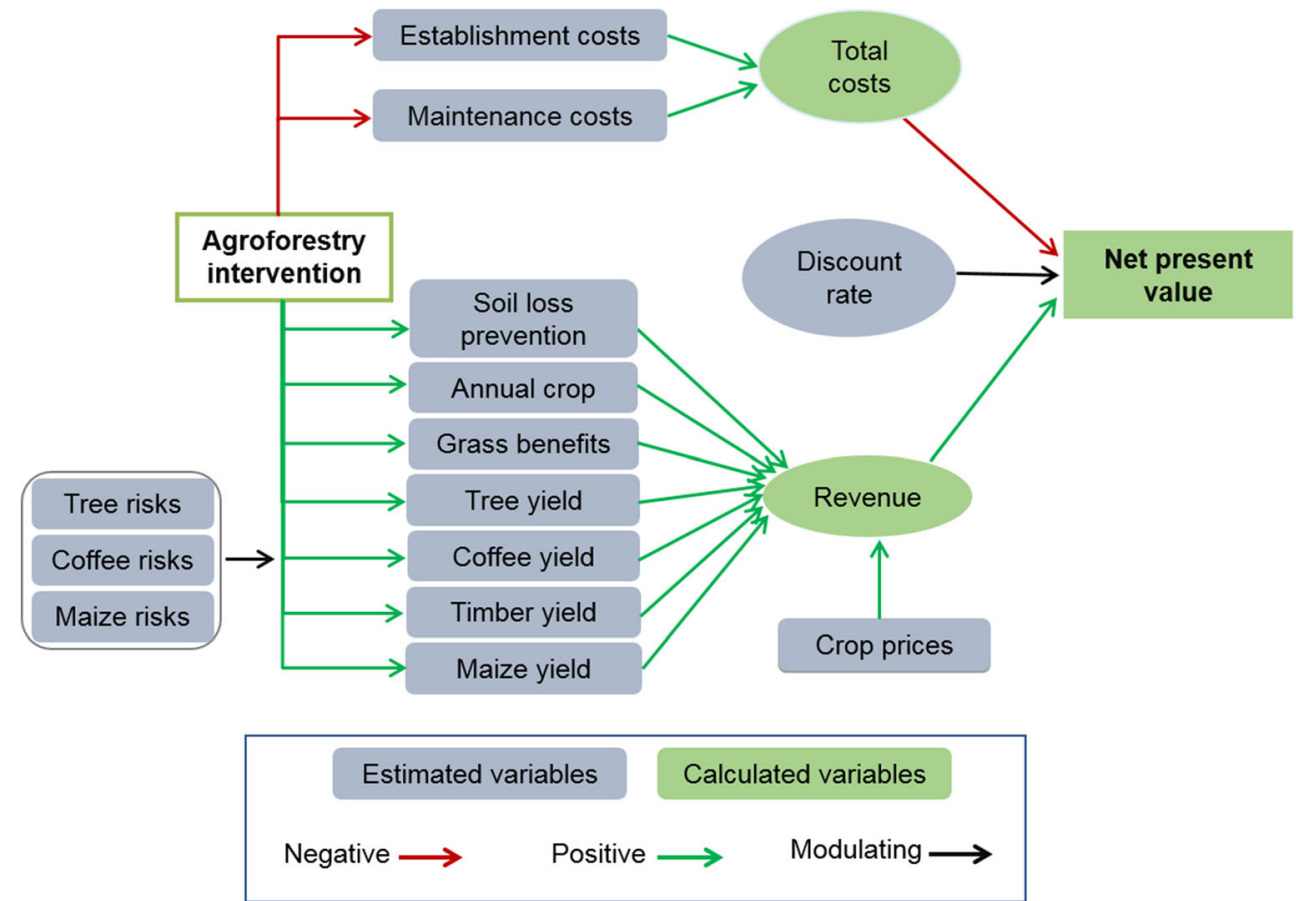


Table 1 Expected yield losses (90\% confidence interval) due to risk events. Losses were assumed to be normally distributed, truncated at 0 (precluding negative values, which would indicate yield gains). For coffee, where the main risk considered was the occurrence of frost events, the normal distribution was not truncated (allowing for a small chance of yield gains)

\begin{tabular}{lll}
\hline Crop & \multicolumn{2}{l}{ Yield loss (90\% confidence interval) } \\
\cline { 2 - 3 } & Lower bound (\%) & Upper bound (\%) \\
\hline Shan tea & 20 & 40 \\
Son tra & 20 & 50 \\
Longan (maize system) & 50 & 70 \\
Mango & 30 & 50 \\
Plum & 20 & 40 \\
Longan (coffee system) & 30 & 50 \\
Macadamia & 20 & 50 \\
Coffee & 0 & 70 \\
Maize & 20 & 80 \\
\hline
\end{tabular}

model and expressed their relationships using mathematical equations.

\subsubsection{Crop yield patterns}

One important aspect of the model included estimating yields of tree crops over time. We modeled these to follow the pattern of the Gompertz curve (Luedeling et al. 2019). According to this model, tree yields increase over time until reaching a plateau that represents their full productive capacity. This production level is then maintained for the remainder of the tree's productive life. Three critical points were specified to define these yield curves (Fig. 5).

The plateau $Y_{\max }$ of the Gompertz curve is the maximum yield that a tree can attain throughout its life cycle. The curve was parameterized based on yields $Y_{\mathrm{T} 1}$ and $Y_{\mathrm{T} 2}$ at time $T_{1}$ and

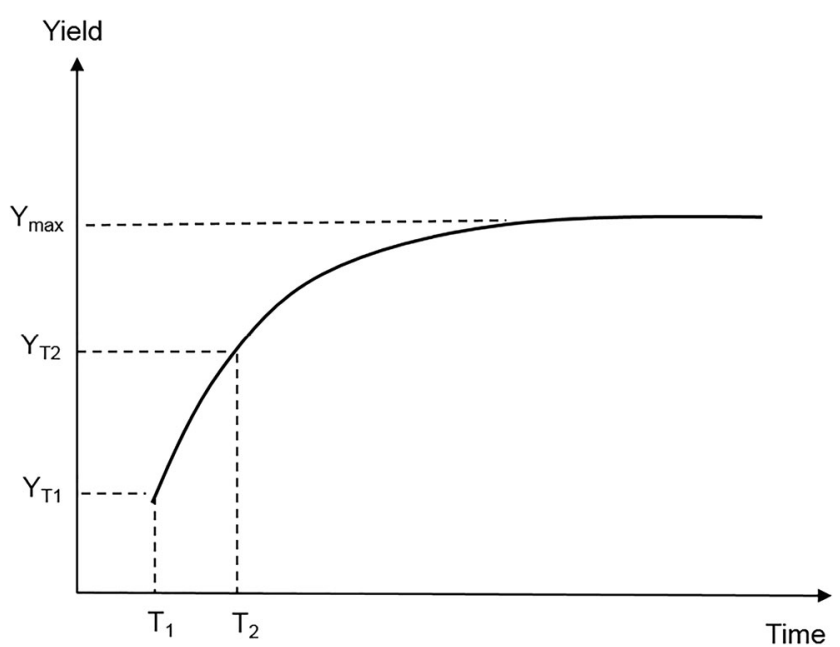

Fig. 5 Gompertz curve describing the yield of tree crops (i.e., Shan tea, son tra, longan, mango, plum, and macadamia)
$T_{2}$, respectively, considering the ages of trees for which participants were best able to provide estimates. The yield of Arabica coffee was simulated with two productive periods following the same Gompertz patterns. The first 15-year productive cycle was followed by a second 10-year productive cycle.

The yield of maize in agroforestry systems was assumed to decline corresponding to an exponential decay function:

$Y=Y_{f}+\left(Y_{o}-Y_{f}\right) e^{-k t}$

in which $Y_{0}$ is the initial maize yield in the year a system is established. $Y_{f}$ is the minimum yield that maize can maintain. The minimum yield reflects the ability of agroforestry to stabilize maize yield during the simulation period. Coefficient $k$ represents how fast maize yield will approach the $Y_{f}$ value, and $t$ indicates the production cycles. This decline was included because space occupation and shading of forage grass and tree components in agroforestry systems are expected to reduce yields over time.

The yield of maize in monoculture stands decreased in response to the decrease in soil organic matter and soil nutrient status in the course of cultivation:

$Y=Y_{o} e^{-k t}$

\subsubsection{Quantification of uncertainties in the model}

We formally represented uncertainties in the model by expressing all variables as probability distributions derived from expert assessments. However, relying on expert judgment requires awareness of the many cognitive biases (Tversky and Kahneman 1974) that can affect experts' ability to provide accurate uncertainty estimates (Uusitalo et al. 2015). Experts often overestimate the precision of their knowledge (Hubbard 2014), are easily influenced by initial estimates or even unrelated numbers (Page et al. 2012), or consider recently experienced or remarkable events to be more common than they actually are (Hubbard 2014). A number of methodologies have been proposed for reducing the influence of such cognitive biases (Page et al. 2012; Hubbard 2014; Luedeling et al. 2015; Whitney et al. 2018). We followed the de-biasing techniques described by Hubbard (2014), known as calibration training, to elicit expert knowledge for both qualitative and quantitative information. During the training, we presented experts with trivia questions and asked them to provide probability distributions of uncertain quantities or quantitatively express their confidence that their answers to true/false questions were correct. We gave them feedback and tools for providing more accurate estimates, which have been shown to lead to a reduction of overconfidence (Hubbard 2014). In this way, we were able to 
increase the accuracy of expert estimates (Hardaker and Lien 2010) and reduce the potential biases associated with the experts' estimations (Page et al. 2012). After experts had participated in the calibration training, they were asked to provide upper and lower bounds of $90 \%$ confidence intervals, as well as distribution shapes for all the input variables of the decision model.

\subsubsection{Calculation of Net Present Value}

The decision model was used to quantify the overall economic outcome for each decision option by calculating the Net Present Value (NPV) over a 25-year period. The comparative financial performance was assessed on the basis of the net benefit per hectare by subtracting costs from revenues for each option. To account for the time preference of money, we used a discounting procedure to convert the net values into financial NPVs:

$\mathrm{NPV}=-C_{0}+\sum_{i=1}^{t} \frac{C_{i}}{(1+r)^{i}}$

$C_{0} \quad$ establishment cost

$C_{i} \quad$ cash flow in year $i$

$r$ discount rate

$t$ time of simulation

\subsection{Probabilistic analysis}

We applied Monte Carlo simulations to generate the ranges of possible values for NPVs of all agroforestry options, as well as for maize monocultures as the baseline system. We ran simulations with 10,000 model runs to generate the distributions of expected NPVs by randomly selecting values from distributions of input variables and feeding them into our mathematical formulation of the decision model.

We applied Projection to Latent Structures (PLS) regression as a sensitivity analysis to identify critical uncertain input variables that best explained variation in NPVs (Luedeling and Gassner 2012). The parameters of interest from this procedure included the variable importance in the projection (VIP) and the regression coefficient. The VIP is a weighted sum of squares with weights calculated from the amount of explained variance for the response variable in each PLS dimension. It represents the contribution of each predictor in fitting the PLS model. The regression coefficient shows the direction and magnitude of the impact of each variable on the PLS model output (Luedeling and Gassner 2012). We used a threshold of VIP = 1 to distinguish between important and unimportant variables (Chong and Jun 2005).
We then applied Value of Information analysis to determine whether collecting additional information on a certain input variable would be warranted for providing more certainty about the most beneficial decision option. We quantified the value of information by computing the expected value of perfect information (EVPI). The EVPI represents the monetary value that would hypothetically be worth investing in order to completely eliminate uncertainty on specified variables in the decision-making process (Hubbard 2014). The EVPI can guide and underpin research priorities, especially in a research environment with limited funding (Luedeling et al. 2015; Whitney et al. 2018).

All model coding and probabilistic analyses were implemented in the $\mathrm{R}$ programming language ( $\mathrm{R}$ Core Team 2018) with functions of the decisionSupport package (Luedeling et al. 2019). The model script and input tables with a full list of variables are provided in supplements (https://doi.org/10. 5281/zenodo.3727576).

\section{Results and discussion}

\subsection{Profitability of agroforestry}

Model simulations revealed wide ranges of possible values for NPVs of all agroforestry options and maize monocultures. Simulations showed an estimated NPV of maize monocultures between -348 USD ha $^{-1}$ and 8360 USD ha $^{-1}$ (90\% confidence interval) after 25 years of continuous cultivation. Agroforestry systems were expected to achieve higher NPVs with a greater chance of high positive outcomes (simulated net benefits; Fig. 6). Models of the two simple agroforestry systems generated $90 \%$ confidence intervals between -1515 USD ha ${ }^{-1}$ and 15,995 USD ha-1 for Shan tea and between $2600 \mathrm{USD} \mathrm{ha}^{-1}$ and $62,889 \mathrm{USD} \mathrm{ha}^{-1}$ for son tra. The two maize-based agroforestry systems were expected to generate NPVs between 4068 USD ha $^{-1}$ and 33,531 USD ha ${ }^{-1}$ for the system with longan and between $3525 \mathrm{USD} \mathrm{ha}^{-1}$ and 22,779 USD ha ${ }^{-1}$ for the system with acacia and mango. In coffeebased agroforestry, a 90\% confidence interval of -561 USD $\mathrm{ha}^{-1}$ to $23,556 \mathrm{USD} \mathrm{ha}^{-1}$ was predicted for the system with macadamia, -467 USD ha $^{-1}$ to 19,888 USD ha $^{-1}$ for the system with teak and plum (CAFS-Teak), and $1208 \mathrm{USD} \mathrm{ha}^{-1}$ to 28,661 USD ha ${ }^{-1}$ for the system with acacia and longan (CAFS-Acacia). A small number of model runs resulted in net losses for both agroforestry and monoculture systems. Specifically, 10,000 model runs of the simple system with Shan tea produced negative outcomes $13.9 \%$ of the time. Coffee-based systems with teak and plum and with macadamia resulted in negative NPVs $7.1 \%$ and $7.5 \%$ of the time, respectively. Models indicated a $7.0 \%$ probability of negative outcomes for the baseline system. 


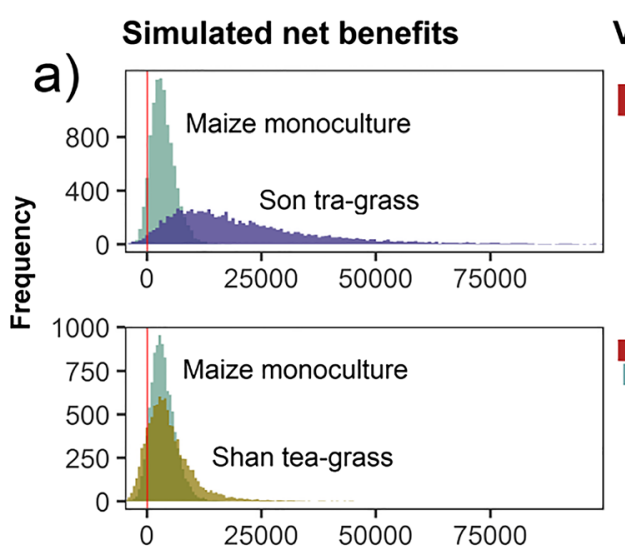

Variable Importance
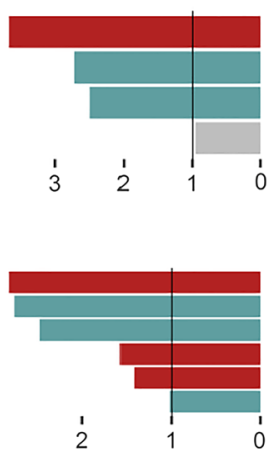

\section{Value of Information}

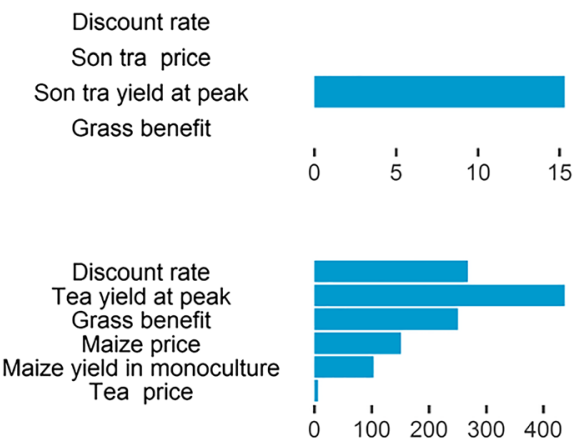

b)
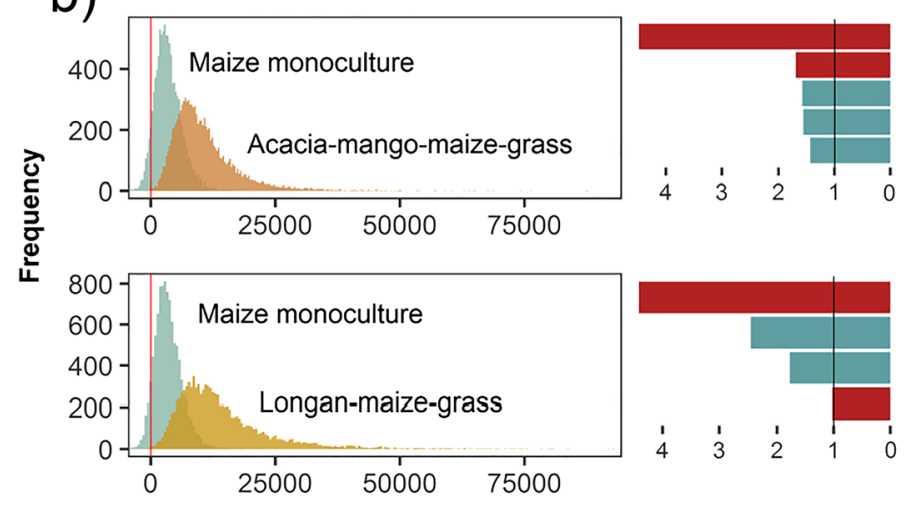

Discount rate Longan yield at peak Longan fruit price Maize yield in monoculture

Discount rate Maize yield in monoculture

Mango price Mango yield at peak Yield of maize in AF system
No variable with information value c)
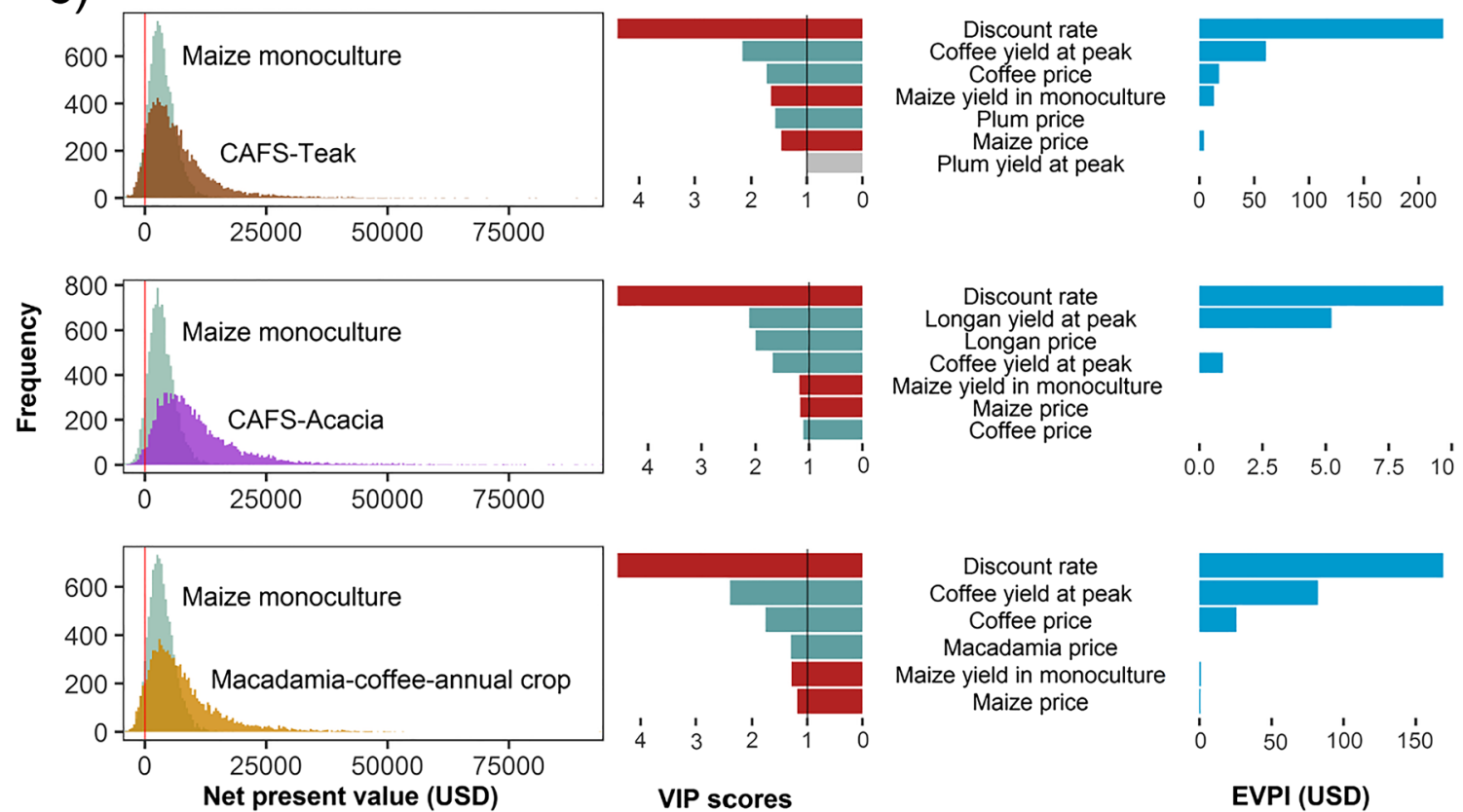

Discount rate Coffee yield at peak Coffee price Macadamia price Maize yield in monoculture Maize price

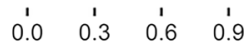

Fig. 6 Probabilistic analysis of agroforestry intervention decisions in Northwestern Vietnam: a implement simple agroforestry systems vs. maize monoculture, $\mathbf{b}$ implement maize-based agroforestry systems vs. maize monoculture, and $\mathbf{c}$ implement coffee-based agroforestry systems vs. maize monoculture. Histograms (left) present the Net Present Values of 10,000 Monte Carlo simulation runs of agroforestry and maize monocultures. Bar graphs (right) indicate variable importance (expressed by VIP scores) for variables to which the model was most sensitive (green bars indicate positive relationships with the outcome variables, red bars indicate negative relationships, gray bars indicate variables with VIP scores less than 1) and value of information calculated as Expected Value of Perfect Information (EVPI) in USD 
These results support ICRAF's intervention to promote agroforestry practices among farmers in mountainous regions of Northwest Vietnam. Nevertheless, despite the relatively low economic return, monocultures of maize still dominate the region (Hoang et al. 2017). The simulations reveal a long time lag before the initial agroforestry investments pay off. This leads to lower short-term profits in agroforestry compared to monocultures, which already begin to generate profits in the first year of production. Due to the early income from maize harvests, the two maize-based agroforestry systems needed only 2 to 3 years before reaching a $50 \%$ chance of positive cumulative cash flow. The simple agroforestry system with son tra took 4 years and Shan tea took 7 years to reach a $50 \%$ chance of positive cumulative cash flow. A similar time lag of 7 to 8 years was also forecast for coffee-based agroforestry systems to compensate for initial investments, despite the early income from annual crops. These lags may be a prohibitively long wait for many resource-constrained small-scale farmers, who have high discount rates (i.e., they strongly prefer benefits now to benefits that occur later) (Pannell et al. 2014). Large investments with time lags for returns, such as agroforestry interventions, can be effective if they are supported, for example, by enabling environments that provide secure land tenure, the support of longterm land-use practices and diversified short-term livelihood options (Sain et al. 2017). The Vietnamese government's new Land Law (45/2013/QH13) seeks to extend farmers' land leases from 20 to 50 years and could encourage long-term investments in permanent land use (Simelton et al. 2017). However, many farmers may not have sufficient savings or access to enough credit to make such investments. The lack of support for and promotion of sustainable land-use practices is a major factor limiting the adoption of agroforestry, including in Vietnam. The currently small estimated compensation (savings in fertilizer to compensate for nutrients lost through soil erosion) may not be enough to incentivize farmers to practice soil conservation. If reasonable monetary incentives were provided to farmers, the adoption of soil conservation practices could increase substantially (Quang et al. 2014). The government's policy on Payments for Ecosystem Services (Decree 99/ 2010/NĐ-CP) aims to maintain and support forestry but not agroforestry (Simelton et al. 2017). A study on the effect of hypothetical monetary incentives for households in Northwest Vietnam to adopt soil-conserving land-use practices found that a payment of 12-16 USD per ton of soil saved would be needed to effect a reduction of $40 \%$ of estimated soil loss (Quang et al. 2014). However, financial incentives for sustainable landuse practices are still lacking.

\subsection{Decision-relevant uncertainties and their value of information}

Across all agroforestry options, VIP scores were considerably higher for discount rates than for other variables, with the discount rate being negatively correlated with NPVs (variable importance; Fig. 6). This indicates that decision outcomes are highly sensitive to the discount rate, with a high discount rate having a negative effect on the decision outcome. Other factors related to fruit tree yield, coffee yield, and the prices of crop and tree products were also marked as key uncertain variables (VIP $\geq 1$ ).

The discount rate of the farmers was a consistently important factor across simulations (VIP scores ranged from 3 to 5). This is consistent with the long time frame of agroforestry practices, which can take several years to begin producing substantive benefits. Farmers have a strong preference for present-day net benefits over future benefits, and they value present pay-offs much more highly than long-term profits in their decision making. Therefore, farmers' discount rates can be decisive for adoption decisions, which often differ substantially among farmers, even for the same technology in the same project area (Hoekstra 1985). Discount rates may vary according to multiple factors, such as farmers' savings, alternative income sources, risk preferences, and degrees of tenure security. Choosing an appropriate discount rate, especially when dealing with subsistence-oriented and resourceconstrained smallholders, is essential for the analysis of agroforestry systems (Hoekstra 1985; Pannell et al. 2014). We based our $90 \%$ confidence interval estimate for the discount rate on a rate used to identify the economic merits of afforestation for rural farm households in Northern Uplands of Vietnam (Nguyen et al. 2010) and a rate used for resourcepoor farmers when analyzing farm-level economics of conservation agriculture (Pannell et al. 2014). The range likely captures the discount rates of the majority of farmers in the region.

Yield variability was a factor of high importance in the model simulations (VIP scores ranged from 1 to 3). Yield variability results from heterogeneous biophysical conditions (e.g., soil properties, precipitation, field slope direction), interactions among tree components in agroforestry systems, and, possibly more importantly, from local socio-economic factors such as farming habits and levels of investment. Northwestern Vietnam features large field-to-field variability in terms of cropping practices, fertilizer use, and soil fertility status, which results in high variability in crop productivity. In this mountainous region, many farmers manage steep terrain in a range of topographic positions, which give rise to substantial spatial variability in soil fertility and crop yields (Wezel et al. 2002).

Crop prices were another set of important uncertainties affecting model outcomes (VIP scores ranged from 1 to 3 ). Experts agreed that crop prices would be influenced by factors such as annual crop productivity, product quality, and farmers' ability to negotiate on prices. This is important, since weak post-harvest technologies and the lack of market information can lead to markets being temporarily flooded with particular agricultural commodities. This often results in price drops during peak harvest seasons. Prices of many crops can 
also be highly uncertain, since they are often set by private middle-men and traders. Additionally, with the exception of a few cooperatives and state-owned enterprises involved in tea and wood processing, policies for markets and product distribution are largely missing in the agroforestry value chain (Simelton et al. 2017), especially markets for new agroforestry products that work effectively even when agroforestry practices are widely adopted and scaled up to larger areas.

Resource-poor farmers often need to prioritize their families' immediate needs and do not have the luxury of being able to make income sacrifices in the short term. Even if practices can result in higher long-term benefits, farmers may still choose lower short-term benefits (Pannell et al. 2014). Likewise, small farmers are riskaverse and often tend to choose practices with low investment requirements and highly certain economic returns. They are less likely to adopt new agricultural practices with uncertain costs, crop yields, and output prices relative to those of conventional practices. However, critically, due mainly to their unsustainable mining of soil nutrients and high levels of erosion, projected annual profits of maize monoculture systems decrease over time. This option, although regionally dominant at the moment, cannot reasonably be expected to remain the dominant system in the future. Experiences from farmer-driven cooperatives of small-scale organic producers in Vietnam propose potential solutions to address some of the challenges to agroforestry adoption. Cooperatives, with clear leadership structures and predictable commitments by a number of farmers, offer opportunities for producing agricultural commodities in a more standardized way. They can thus facilitate a regular supply of products with homogenous quality, allowing farmers to access markets that may otherwise be beyond their reach and opening prospects for stable and high sale prices (Islam et al. 2018). Production cooperatives can also empower smallholder farmers by facilitating the exchange of skills and knowledge on crop production and marketing. Supporting policies for establishing effective farmer cooperatives in agroforestry could be instrumental in promoting this farming practice.

All variables in models for simple agroforestry with son tra and grass (value of information, Fig. 6a), two maize-based systems (value of information, Fig. 6b), and the coffee-based system CAFS-Acacia (value of information, Fig. 6c) had either no information value or very low values of the EVPI. The remaining systems had non-zero EVPI for discount rates, coffee yield, and coffee prices (value of information, Fig. 6c), tea yield, the yield of maize in monoculture, and maize price (value of information, Fig. 6a). Collecting additional information on the variables that have non-zero EVPI could be helpful for better determining whether farmers should be incentivized to choose maize monoculture or the respective agroforestry options. Nevertheless, decision-makers should not be willing to spend more than the estimated amounts (EVPI) for further investigating selected variables. The lack of information value for many variables (i.e., EVPI $=0$ ) suggests that no further evidence would be helpful for making a better decision when choosing agroforestry systems over monoculture. The differences in the forecasted decision outcomes (simulated net benefits, Fig. 6) already offer high confidence in agroforestry being the more sustainable long-term solution. No further evidence should be necessary for appropriate supporting policies to be put into place to facilitate the implementation of agroforestry interventions.

\subsection{Probabilistic analysis of agroforestry systems}

The modeling approaches we applied allowed for the incorporation of expert knowledge and elicitation of uncertainties. In this way, the model reflects the high variability in local farming systems in aspects such as cropping practices, fertilizer use, soil fertility, and resulting crop yields in Northern Vietnam. The uncertainties, elicited from experts for feeding the model, reflect the current state of the participants' knowledge on each agroforestry system. The model in this study presents the costs and benefits of agroforestry systems at the farm level only. Other factors may also be important to the wider social and ecological systems surrounding these farms. However, off-farm benefits of agroforestry, such as those provided to local communities, may be important from a social perspective but may not influence the decision-making of resource-poor smallholder farmers (Das and Bauer, 2012). This study provided an analysis of the economic returns, which is the priority for local farmers (Simelton et al. 2017) and is considered critical by ICRAF and governmental stakeholders (La 2018, personal communication). The results constitute a solid background for further analyses on farmers' adoption of agroforestry by taking a broad view of the diverse factors that influence regional land-use systems. During adoption, farmers may modify or adapt agroforestry innovations to their circumstances. Instead of an abrupt change from a monoculture system to an entirely new agroforestry system, which may require a large investment and reduce the short-term returns from the land, gradual transition in the implementation of agroforestry is a potential decision alternative, especially for resource-poor farmers. Such a gradual transition could be an alternative approach for ICRAF Vietnam to improve the feasibility of agroforestry implementation in the local context. To more fully capture the current situation of smallholder farmers in the target region, assessment of the relative profitability of agroforestry practices compared to other major land-use types, such as the 
production of cassava or upland rice, may also be needed. The holistic modeling approach demonstrated in this analysis can easily be tailored to compare a greater number of land use options, allowing customized assessments that serve the needs of different decision makers.

\section{Conclusion}

We present an innovative approach for supporting complex decisions. We apply expert knowledge in the design and parameterization of models of costs, benefits, risks, and uncertainties associated with adopting various agroforestry options. All modeled agroforestry systems offer positive returns in the long term. However, high establishment and maintenance costs reduce economic returns in the short term, generating time lags of more than 3 years, which may be too long for most smallholder farmers. The currently dominant practice of maize monoculture may be preferred for the relatively early lag-free returns, yet in this system, annual profits decrease over time. Agroforestry systems outperform maize monocultures in the long term, yet the required investments may not be economically viable for farmers in the short term. Economic incentives that compensate for these short-term losses can aid in agroforestry promotion. A better understanding of uncertain factors such as the discount rate, crop yields, and crop prices may be useful for supporting agroforestry decisions. The results and methods of this study promise to be useful in the design of future policies for sustainable development and for further analyses of agroforestry interventions.

Acknowledgments We appreciate the active participation of researchers and technical staff of World Agroforestry (ICRAF) in Vietnam, especially the AFLi team. Thank you to the scientists of the Vietnam National University of Agriculture, experts of the Northern Mountainous Agriculture and Forestry Science Institute and local farmers for their support during field research, and the reviewers for their critical feedback that improved this manuscript. We thank the German Academic Exchange Service (DAAD) for providing funding for field research in Vietnam.

Statement of data availability All data generated during this study are available in the repository https://doi.org/10.5281/zenodo.3727576.

Author contributions Conceptualization, H.D., C.W., and E.L.; Methodology, H.D., C.W., and E.L.; Investigation, H.D.; Visualization, H.D., C.W., and E.L; Writing — original draft, H.D. Writing - review \& editing, E.L. and C.W.; Software, E.L.; Funding acquisition, H.D.; Supervision, C.W. and E.L.

Funding Information Open Access funding provided by Projekt DEAL.

\section{Compliance with ethical standards}

Conflict of interest The authors declare that they have no conflicts of interest.
Open Access This article is licensed under a Creative Commons Attribution 4.0 International License, which permits use, sharing, adaptation, distribution and reproduction in any medium or format, as long as you give appropriate credit to the original author(s) and the source, provide a link to the Creative Commons licence, and indicate if changes were made. The images or other third party material in this article are included in the article's Creative Commons licence, unless indicated otherwise in a credit line to the material. If material is not included in the article's Creative Commons licence and your intended use is not permitted by statutory regulation or exceeds the permitted use, you will need to obtain permission directly from the copyright holder. To view a copy of this licence, visit http://creativecommons.org/licenses/by/4.0/.

\section{References}

Chong I-G, Jun C-H (2005) Performance of some variable selection methods when multicollinearity is present. Chemom Intell Lab Syst 78:103-112. https://doi.org/10.1016/j.chemolab.2004.12.011

Das R, Bauer S (2012) Bio-economic analysis of soil conservation technologies in the mid-hill region of Nepal. Soil Tillage Res 121:38-48. https://doi.org/10.1016/j.still.2012.01.016

Davidson VJ, Ryks J, Fazil A (2006) Fuzzy risk assessment tool for microbial hazards in food systems. Fuzzy Sets Syst 157:12011210. https://doi.org/10.1016/j.fss.2005.12.018

Hardaker JB, Lien G (2010) Probabilities for decision analysis in agriculture and rural resource economics: the need for a paradigm change. Agric Syst 103:345-350. https://doi.org/10.1016/j.agsy.2010.01. 001

Hoang LT, Roshetko JM, Huu TP, Pagella T, Mai PN (2017) Agroforestry - the most resilient farming system for the hilly Northwest of Vietnam. Int J Agric Syst 5:1. https://doi.org/10. 20956/ijas.v5i1.1166

Hoekstra DA (1985) Choosing the discount rate for analysing agroforestry systems/technologies from a private economic viewpoint. For Ecol Manag 10:177-183. https://doi.org/10.1016/0378-1127(85) 90020-9

Hubbard DW (2014) How to measure anything: finding the value of "intangibles" in business, 3rd edn. Wiley, Hoboken, N.J

Islam K, Fujiwara T, Sato N, Hyakumura K (2018) Evolving and strengthening the cooperative approach for agroforestry farmers in Bangladesh: lessons learned from the Shimogo Cooperative in Japan. Sustainability 10:617. https://doi.org/10.3390/su10030617

Krueger T, Page T, Hubacek K, Smith L, Hiscock K (2012) The role of expert opinion in environmental modelling. Environ Model Softw 36:4-18. https://doi.org/10.1016/j.envsoft.2012.01.011

Kuyah S, Whitney CW, Jonsson M, Sileshi GW, Öborn I, Muthuri CW, Luedeling E (2019) Agroforestry delivers a win-win solution for ecosystem services in sub-Saharan Africa. A meta-analysis. Agron Sustain Dev 39:47. https://doi.org/10.1007/s13593-019-0589-8

Luedeling E, Gassner A (2012) Partial Least Squares Regression for analyzing walnut phenology in California. Agric For Meteorol 158-159:43-52. https://doi.org/10.1016/j.agrformet.2011.10.020

Luedeling E, Shepherd K (2016) Decision-focused agricultural research. Solutions 7:46-54

Luedeling E, Kindt R, Huth NI, Koenig K (2014) Agroforestry systems in a changing climate - challenges in projecting future performance. Curr Opin Environ Sustain 6:1-7. https://doi.org/10.1016/j.cosust. 2013.07.013

Luedeling E, Oord AL, Kiteme B, Ogalleh S, Malesu M, Shepherd KD, de Leeuw J (2015) Fresh groundwater for Wajir-ex-ante assessment of uncertain benefits for multiple stakeholders in a water supply 
project in Northern Kenya. Front Environ Sci 3. https://doi.org/10. 3389/fenvs.2015.00016

Luedeling E, Goehring L, Schiffers K (2019) decisionSupport: quantitative support of decision making under uncertainty. R package version 1.105 .2

Mbow C, Van Noordwijk M, Luedeling E et al (2014) Agroforestry solutions to address food security and climate change challenges in Africa. Curr Opin Environ Sustain 6:61-67. https://doi.org/10. 1016/j.cosust.2013.10.014

Nguyen TT, Bauer S, Uibrig H (2010) Land privatization and afforestation incentive of rural farms in the Northern Uplands of Vietnam. Forest Policy Econ 12:518-526. https://doi.org/10.1016/j.forpol. 2010.05.007

Nguyen HN, Van de Fliert E, Nicetic O (2015) Towards a holistic framework for impact assessment of agricultural research for development - understanding complexity in remote, culturally diverse regions of Vietnam. Aust Agribus Rev 23:12-25. https://doi.org/10.22004/ag. econ. 262470

O'Hagan A (2012) Probabilistic uncertainty specification: overview, elaboration techniques and their application to a mechanistic model of carbon flux. Environ Model Softw 36:35-48. https://doi.org/10. 1016/j.envsoft.2011.03.003

Oliver DM, Fish RD, Winter M, Hodgson CJ, Heathwaite AL, Chadwick DR (2012) Valuing local knowledge as a source of expert data: farmer engagement and the design of decision support systems. Environ Model Softw 36:76-85. https://doi.org/10.1016/j.envsoft. 2011.09.013

Page T, Heathwaite AL, Thompson LJ, Pope L, Willows R (2012) Eliciting fuzzy distributions from experts for ranking conceptual risk model components. Environ Model Softw 36:19-34. https://doi.org/ 10.1016/j.envsoft.2011.03.001

Pannell DJ, Llewellyn RS, Corbeels M (2014) The farm-level economics of conservation agriculture for resource-poor farmers. Agric Ecosyst Environ 187:52-64. https://doi.org/10.1016/j.agee.2013.10.014

Quang DV, Schreinemachers P, Berger T (2014) Ex-ante assessment of soil conservation methods in the uplands of Vietnam: an agentbased modeling approach. Agric Syst 123:108-119. https://doi. org/10.1016/j.agsy.2013.10.002
R Core Team (2018) R: a language and environment for statistical computing. R Foundation for Statistical Computing, Vienna, Austria

Rosenstock TS, Mpanda M, Rioux J, Aynekulu E, Kimaro AA, Neufeldt H, Shepherd KD, Luedeling E (2014) Targeting conservation agriculture in the context of livelihoods and landscapes. Agric Ecosyst Environ 187:47-51. https://doi.org/10.1016/j.agee.2013.11.011

Sain G, Loboguerrero AM, Corner-Dolloff C, Lizarazo M, Nowak A, Martínez-Barón D, Andrieu N (2017) Costs and benefits of climate-smart agriculture: the case of the Dry Corridor in Guatemala. Agric Syst 151:163-173. https://doi.org/10.1016/j. agsy.2016.05.004

Simelton ES, Catacutan DC, Dao TC, Dam BV, le TD (2017) Factors constraining and enabling agroforestry adoption in Viet Nam: a multi-level policy analysis. Agrofor Syst 91:51-67. https://doi.org/ 10.1007/s10457-016-9906-2

Tversky A, Kahneman D (1974) Judgment under uncertainty: heuristics and biases. Science 185:1124-1131. https://doi.org/10.1126/ science.185.4157.1124

Uusitalo L, Lehikoinen A, Helle I, Myrberg K (2015) An overview of methods to evaluate uncertainty of deterministic models in decision support. Environ Model Softw 63:24-31. https://doi.org/10.1016/j. envsoft.2014.09.017

Wezel A, Steinmüller N, Friederichsen JR (2002) Slope position effects on soil fertility and crop productivity and implications for soil conservation in upland northwest Vietnam. Agric Ecosyst Environ 91: 113-126. https://doi.org/10.1016/S0167-8809(01)00242-0

Whitney CW, Tabuti JRS, Hensel O, Yeh CH, Gebauer J, Luedeling E (2017) Homegardens and the future of food and nutrition security in southwest Uganda. Agric Syst 154:133-144. https://doi.org/10. 1016/j.agsy.2017.03.009

Whitney CW, Lanzanova D, Muchiri C, Shepherd KD, Rosenstock TS, Krawinkel M, Tabuti JRS, Luedeling E (2018) Probabilistic decision tools for determining impacts of agricultural development policy on household nutrition. Earth's Future 6:359-372. https://doi. org/10.1002/2017EF000765

Publisher's note Springer Nature remains neutral with regard to jurisdictional claims in published maps and institutional affiliations. 